\author{
Cornelia Schaefer-Prokop \\ Ulrich Neitzel \\ Henk W. Venema \\ Martin Uffmann \\ Mathias Prokop
}

\section{Digital chest radiography: an update on modern technology, dose containment and control of image quality}

Received: 2 May 2007

Revised: 8 February 2008

Accepted: 20 February 2008

Published online: 23 April 2008

(C) The Author(s) 2008

C. Schaefer-Prokop $(\bowtie)$.

H. W. Venema

Department of Radiology,

Academic Medical Center Amsterdam, Meibergdreef 9 ,

1105AZ Amsterdam, The Netherlands e-mail: cornelia.schaeferprokop@

gmail.com

Tel.: +31-20-5669111

U. Neitzel

Clinical Science and Technology

Management X-ray, Philips Healthcare,

Philips Medical Systems DMC GmbH,

Röntgenstrasse 24,

22335 Hamburg, Germany

M. Uffmann

Department of Radiology, General

Hospital Vienna, University of Vienna,

Waehringer Guertel 18-20,

1090 Vienna, Austria

\author{
M. Prokop \\ Department of Radiology, \\ Utrecht Medical Center, \\ Heidelberglaan 100 , \\ 3584 CX Utrecht, The Netherlands
}

\begin{abstract}
The introduction of digital radiography not only has revolutionized communication between radiologists and clinicians, but also has improved image quality and allowed for further reduction of patient exposure. However, digital radiography also poses risks, such as unnoticed increases in patient dose and suboptimum image processing that may lead to suppression of diagnostic information. Advanced processing techniques, such as temporal subtraction, dualenergy subtraction and computeraided detection (CAD) will play an increasing role in the future and are all targeted to decrease the influence of distracting anatomic background
\end{abstract}

structures and to ease the detection of focal and subtle lesions. This review summarizes the most recent technical developments with regard to new detector techniques, options for dose reduction and optimized image processing. It explains the meaning of the exposure indicator or the dose reference level as tools for the radiologist to control the dose. It also provides an overview over the multitude of studies conducted in recent years to evaluate the options of these new developments to realize the principle of ALARA. The focus of the review is hereby on adult applications, the relationship between dose and image quality and the differences between the various detector systems.

Keywords Digital radiography . Chest radiography $\cdot$ Radiation exposure $\cdot$ Digital detector systems · Image quality

\section{Digital chest radiography: an update on modern technology,} dose containment and control of image quality

Chest radiography still remains the mainstay of chest imaging despite the known diagnostic superiority and increasing availability of cross-sectional techniques. The main advantages of chest radiographs are the speed at which they can be acquired and interpreted, the low cost and the low radiation exposure. Upright chest radiographs still play an important role as a fast tool to rule out various chest diseases and cardiac congestion or to monitor response to therapy. Portable radiographs are the main tools to monitor patients in intensive care units (ICU). Chest radiography is responsible for approximately 30 $40 \%$ of all X-ray examinations performed, regardless of the level of health-care delivery [1].

Chest radiography is subject to a number of technical challenges that include capturing the wide attenuation differences between lungs and mediastinum, a need for depiction of small contrast differences and fine structural detail. As a consequence, a radiographic system needs to a have a wide dynamic range in order to display mediastinal 
and retrocardiac abnormalities, should provide a high local contrast to detect focal lesions with subtle contrast and should have a high spatial resolution in order to be able to display interstitial lung disease. For portable chest radiographs, which are usually obtained without grid, the scatter within the patient is the main challenge: retaining contrast in high-attenuation areas such as the mediastinum and retrocardiac regions is more important than high spatial resolution or wide dynamic range.

The introduction of digital radiography not only has revolutionized communication between radiologists and clinicians, but also has improved image quality and allowed for further reduction of the radiation exposure of the patients. However, digital radiography also poses risks: increase in patient dose may go unnoticed because increased dose no longer leads to overexposed films, and suboptimum image processing may lead to suppression of diagnostic information.

Advanced techniques such as temporal subtraction, dual energy subtraction, digital tomosynthesis and computer-aided detection (CAD) may play an increasing role in the future and are all targeted towards better detection and interpretation of chest radiographs in an environment in which time pressure and 24-h availability of constantly high quality image interpretation have a growing importance.

The following article summarizes recent advances in detector technology and discusses radiation-dose control and improvements in image processing.

\section{Developments in detector and readout technology}

Main objectives for recent system developments were

1. to increase dose efficiency,

2. to increase image quality and

3. to ease handling and increase image throughput.

Increased dose efficiency can be used to improve image quality or decrease patient exposure. Ease of handling and increased throughput can be realized through cassette-less handling or instantaneous image availability.

The two most important objective performance measures to describe digital radiography systems with respect to dose requirements and detail resolution are the modulation transfer function (MTF) and the detective quantum efficiency (DQE) [2]. DQE describes the efficiency of a detector to generate signal from X-ray quanta. MTF is a measure of image quality of an imaging system with respect to structural contrast and spatial resolution. Optimizing MTF and DQE simultaneously is a challenge: thicker detector material, for example, will improve absorption (thus, DQE), but generally also will induce more blur (deteriorate MTF).

The following sections discuss recent developments for the three main digital detector technologies: storage phosphors (computed radiography; CR), flat-panel detectors (digital radiography; DR) and CCD detectors.

Storage phosphor radiography (computed radiography, CR)

Computed radiography systems are based on storage phosphor technology that has continuously improved over 25 years. CR systems are relatively inexpensive and versatile: they can be cassette-based and portable, which makes them ideal for bedside imaging, or they can be integrated into a dedicated Bucky system for chest radiography. Standard CR systems use a single laser beam and a detector screen covered with an amorphous (powder-based) detector material (Fig. 1a). These systems require an exposure comparable to a 400 speed film/screen system (detector dose $2.5 \mu \mathrm{Gy}$ ). Recently, a number of improvements regarding detector material and read-out technology have been introduced.

\section{Dual-reading $C R$}

Dual-reading CR systems are based on transparent detector material and employ light collection optics in the front and the back side of the detector (Fig. 2). Combining these signals improves quantum detection (DQE) and has only a minimum deteriorating effect on spatial resolution (MTF) [3].

Dual-reading CR was shown to provide better detection of (simulated) chest lesions than single-reading CR [4]. In the lung fields, but not the mediastinum, detection was even found to be similar to that with high-end DR systems [CsI-photodiode/TFT-(thin-film transistors) detector].

\section{Parallel reading (line scanning)}

Traditional CR scanners use for read-out the principle of flying spot scanning: a tightly focused laser beam stimulates the latent image in a moving storage phosphor plate one point at a time over the entire screen surface. Parallel reading employs a linear array of laser diodes (linear-line laser diode) that reads out all pixels in one line simultaneously, therefore speeding up the process tremendously. A light collection system with dedicated optics and multiple linear asymmetric CCDs also makes the read-out process more effective in terms of photon collection [5].

\section{Needle-crystalline $C R$ detectors}

A new crystalline detector material $\left(\mathrm{CsBr}: \mathrm{Eu}^{2+}\right)$ for storage phosphor systems allows for creating a thicker detector layer (better DQE) without deteriorating spatial resolution 

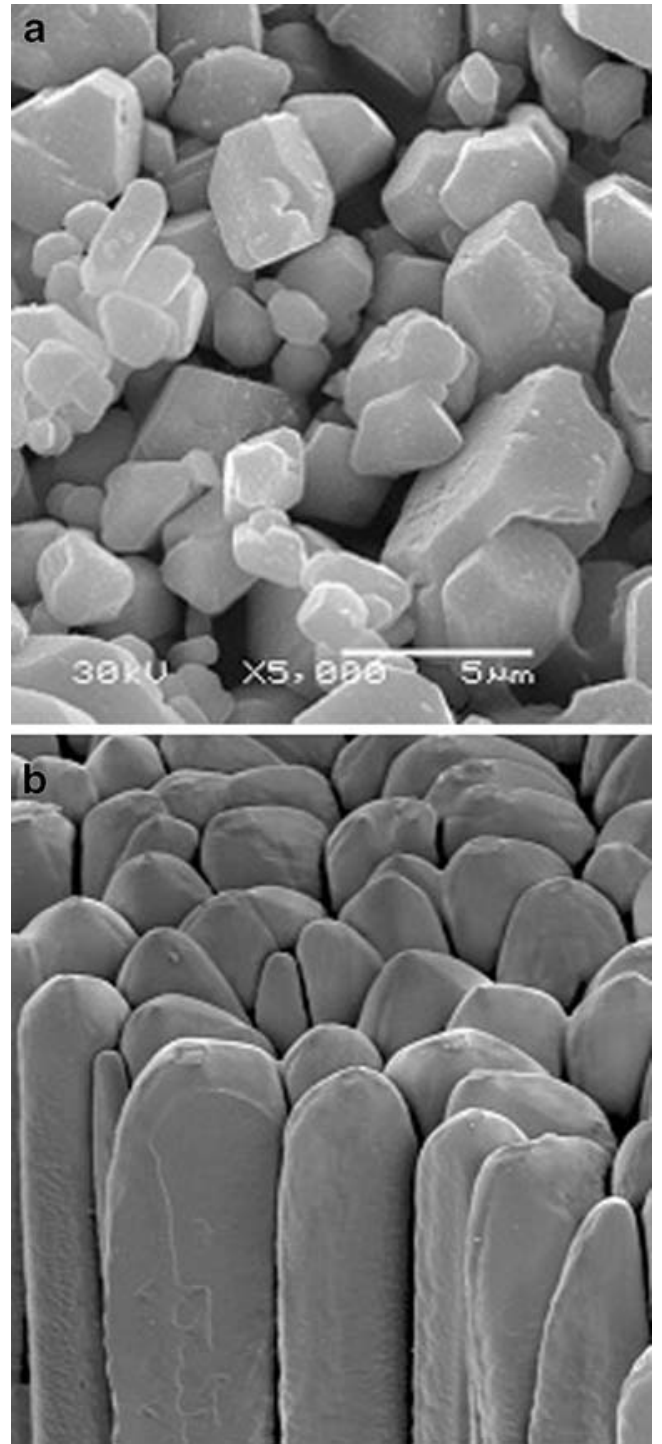

Fig. 1 Electron microscopic views from a powder- (a) and a needlestructured (b) storage phosphor plate (courtesy of Dr. Schaetzing, Agfa, Mortsel, Belgium)

(MTF). This is possible because of the structure of the detector material: crystalline needles serve as light pipes and substantially reduce lateral diffusion of photons. The principle is similar to that of indirect flat panel systems (CsI-photodiode/TFT detectors). Quantum efficiency and detail resolution (sensitivity and sharpness) of a 500- $\mu \mathrm{m}$ thick $\mathrm{CsBr}: \mathrm{Eu}^{2+}$ needle detector, which was read out by the new line scanner, were superior to standard CR systems and matched the values of a CsI-photodiode/TFT detector $[6,7]$.

Initial clinical experience at the bedside and a contrastdetail study found a superior low-contrast resolution and a potential for dose reduction without loss of image quality with the new needle-image-plate/line scanner (NI) as compared to the standard powder image plate/flying spot scanner (PIP) [8, 9] (Figs. 1b, 3).

\section{$4 K$ matrix size}

CR systems with a pixel size of $200 \mu \mathrm{m}$ result in an image matrix of approximately $2,150 \times 1,750$ for a $35 \times 43-\mathrm{cm}$ radiograph. The cut-off frequency of the MTF for these standard ' $2 \mathrm{k}$ matrices' is 2.5 cycles $/ \mathrm{mm}\left(\mathrm{mm}^{-1}\right)$. To allow for a higher spatial resolution with a cut-off frequency of five cycles $/ \mathrm{mm}\left(\mathrm{mm}^{-1}\right)$, all vendors now offer also ' $4 \mathrm{k}$ matrices' with a pixel size of $100 \mu \mathrm{m}$. If pixel size was the limiting factor for image quality, then these systems should provide better clinical results. However, the MTF and DQE above 2.5 cycles $/ \mathrm{mm}\left(\mathrm{mm}^{-1)}\right.$ are both relatively poor for CR systems $[10,11]$. In the low and medium frequency range representing larger, but ill-defined and potentially low contrast structures in the chest, such as infiltrates or tumors, the MTF for 4k images was even lower than that of $2 \mathrm{k}$ images (Fig. 4).
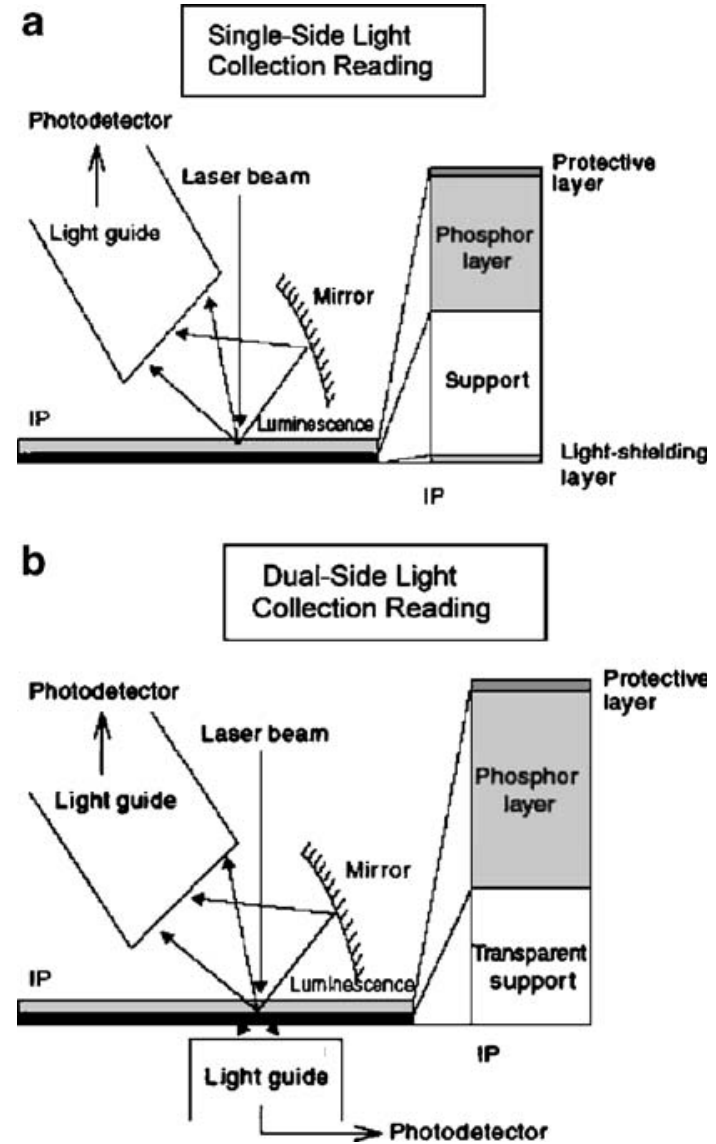

Fig. 2 Schematic view from a single read out (a) and a dual readout (b) system of a storage phosphor plate 


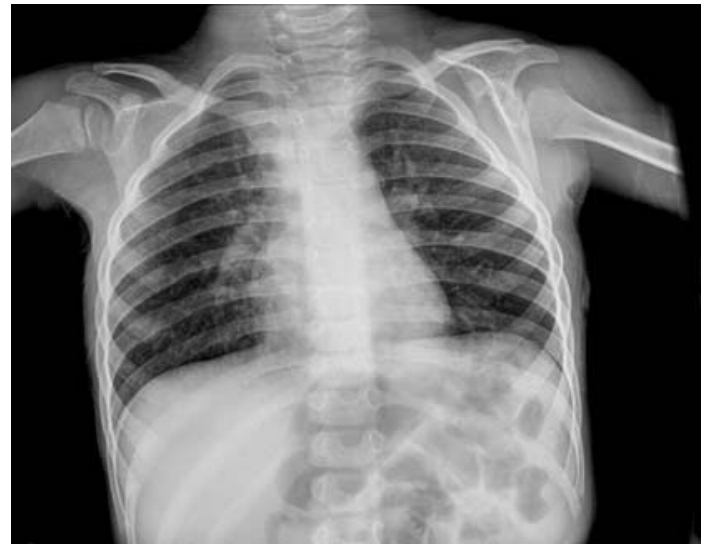

Fig. 3 Postero-anterior radiograph of 3-year-old boy obtained with a needle-structured phosphor plate at 30\% reduced acquisition dose (speed 600) (courtesy of Dr. Koerner, Grosshadern, Munich, Germany)

These experimental data explain that a number of clinical studies could not find an advantage of $4 \mathrm{k}$ matrices for detection of a broad range of intrapulmonary lesions $[12,13]$, delineation of anatomical landmarks [13] or interstitial diseases [14].
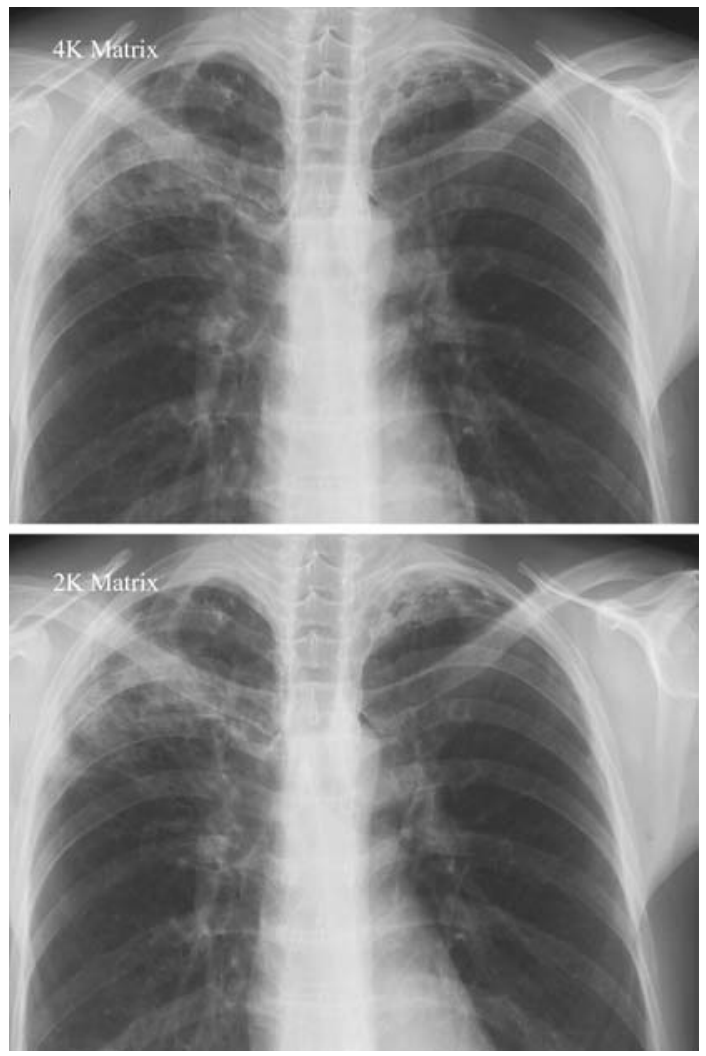

Fig. 4 Storage phosphor radiographs of a patient with right-sided upper-lobe infiltrate obtained with $2 \mathrm{~K}$ and $4 \mathrm{~K}$ matrix size: there is no visually appreciable difference between the images
Flat-panel direct detector systems (DR)

Electronic flat panel detector (DR) systems have been introduced in the past decade. Compared to CR, dedicated Bucky chest units based on DR provide superior image quality and require no transport to an external read-out unit so that the image is instantly available. Recently, a mobile DR system for portable imaging has been introduced. It also offers immediate read-out for visual control of image quality, but suffers from a relatively bulky read-out unit that has to be managed within the patient room.

Two different DR technologies are available, both of which are based on TFT matrix arrays.

Indirect conversion systems or opto-direct systems use a scintillator (e.g., cesium iodide, CsI or gadolinium oxysulphide, GOS or Gadox) layered on top of an array with light-sensitive photodiodes with thin-film transistors (TFTs). The scintillator converts radiation into light that is detected by the photodiode/TFT array. Crystalline scintillators (e.g., CsI) guide the scintillation light through crystalline needles, allowing for thicker detector layers without deteriorating MTF. CsI-photodiode/TFT systems are widely used for chest radiography and provide better DQE than standard CR or Gadox-TFT systems (Fig. 5) $[15,16]$.

Direct conversion systems or electro-direct systems use a photoconducting layer (amorphous selenium, a-Se), in which the absorbed X-ray energy is directly converted into charge on top of a TFT array. These systems are excellent for the high spatial frequencies required for mammography, but because they absorb less X-ray energy, they suffer from a lower dose efficiency (DQE) for structures such as vascular or interstitial structures or infiltrates in the lung represented by frequencies below four cycles $/ \mathrm{mm}$ (factor of 2 compared to CsI-photodiode/TFT), which makes them less suited for chest radiography $[15,17]$.

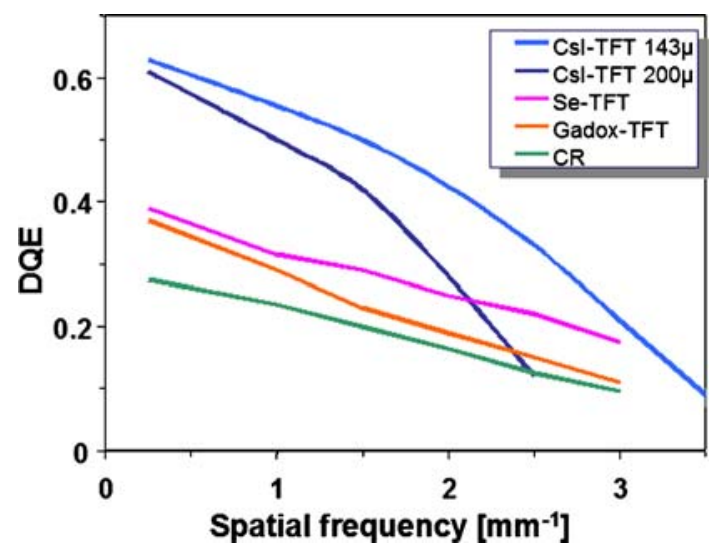

Fig. 5 DQE curves for various detector systems: note the superiority of CsI-TFT over Se- and Gadox-TFT for spatial frequencies below two cycles/mm (source NHS/Kcare UK 2005) 


\section{CCD detector technology}

Charge-coupled devices (CCDs) used to be less well suited for chest radiography because CCDs are much smaller (2$4 \mathrm{~cm}^{2}$ ) than the exposed chest region. The light emitted by a scintillator screen has to be collimated to the CCD by optical coupling (demagnification), which can reduce dose efficiency and degrade image quality [18]. Recent improvements in coupling mechanism and use of larger CCD sensors have made these systems more attractive for chest radiography [19]. Systems are more frequently used in the US than in Western Europe.

\section{Slot-scanning CCD technology}

No demagnification is required for slot-scanning CCD technology: a CsI scintillator is coupled to a linear array of CCDs that covers the whole slot that is used to scan the chest (Fig. 6). The slot-scan technology provides excellent scatter rejection by irradiating the body by a sliding slit beam instead of irradiating the whole body at once. The increased signal to noise yielded by scatter reduction effectively compensates for the 2.5 times lower intrinsic DQE of CCD technology [20]. The increased SNR can be used to improve image quality or to reduce patient dose. In a comparison study of eight digital chest systems, CCD slot-scan technology performed equivalently to CsI-DR. Despite a 75\% dose reduction for CsIDR and a 50\% reduction for CCD slot scanning, both outperformed a standard CR system [21, 22]. Advantages of the CCD technology were especially prominent for the mediastinum [23].

\section{Dose control: why and how?}

\section{Dose creep}

The automatic optimization of image contrast and density in digital radiography systems makes it impossible to determine if a radiograph was over- or underexposed by judging its density. Instead, underexposure manifests itself as an increased image noise while overexposure is rewarded by high image quality. When exposure parameters are chosen manually, such as in portable chest radiography or pediatric exams, radiographers tend to favor overexposure over underexposure because the latter will lead to complaints, while the former will not. The resulting 'dose creep' will cause a gradual increase in exposure parameters over time. This is less important for a single exposure given the relatively low dose of $0.03 \mathrm{mSv}$ for a posteroanterior and lateral chest X-ray compared to the natural burden of radiation, which amounts in most European countries to some $2-3 \mathrm{mSv} /$ year. Nevertheless, dose creep is very important when multiple follow-up
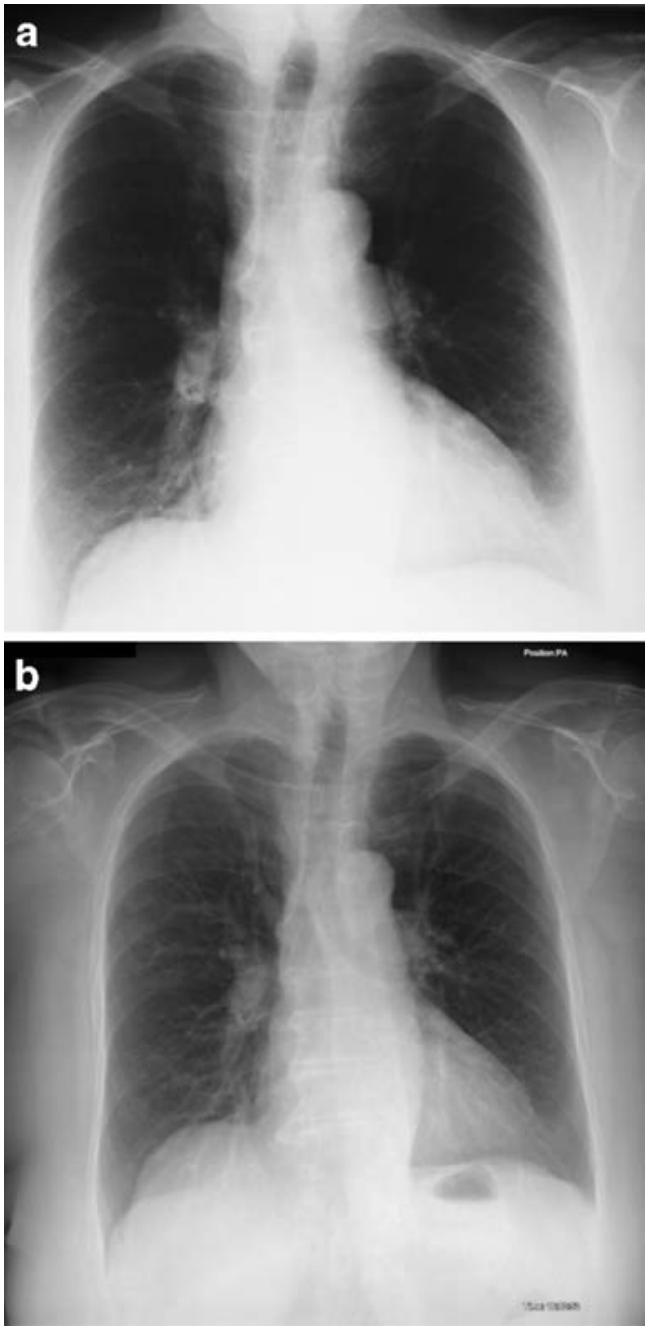

Fig. 6 Considerably increased transparency of high absorption areas in the PA chest radiograph obtained with the slot-scan CCD technique (b) compared to the film/screen radiograph (a) (courtesy of Dr. L. Kroft, LUMC, Leiden, The Netherlands)

examinations are performed (e.g., on intensive care units) or when patients are especially vulnerable (as the pediatric age group).

Compared to conventional radiography, a study in 269 patients admitted to the ICU found that technologists used a significantly higher entrance dose (median 0.21 vs. $0.16 \mathrm{mGy}$ ) for CR [24]. This was seen despite the fact that radiologists will only complain about the noise in CR images when images were underexposed by considerably more than $50 \%$ of the appropriate level [25]. On the other hand, standard CR systems will not profit from an increase in dose level beyond that of a 400 speed film/screen system for imaging tasks such as detection of catheters in the mediastinum [26]. These examples illustrate that there is a need for an exposure indicator that allows for controlling dose in an individual patient as well as for a certain type of examination in a whole patient group. 
Exposure indicators

An exposure indicator or exposure index (EI) gives the user feedback about the actual detector dose level of a digital clinical radiograph. The exposure indicator is always a measure for the air kerma at the detector surface and therefore describes the detector dose and not the patient entrance dose. Unfortunately, the definition of exposure indicators varies between vendors (Fig. 7), which makes it difficult to compare exposure values across systems. Presently, the American Association of Physics in Medicine (AAPM) and the International Electrotechnical Committee (IEC) attempt standardization of the exposure indicator.

The exposure indicator provides a composite measure of radiation exposure and patient-related features. Variation of the EI may be due to varying radiation exposure, but can also be caused by varying clinical conditions (e.g., resolution of pneumonia), patient positioning, and variable focus-detector distance or beam collimation. With automatic exposure control, the EI was shown to be constant within a narrow range [27]. In an ICU setting where automatic exposure control is not available, our own measurements found that the S-value, which is the exposure indicator in Fuji-based CR systems, vary up to $50 \%$ in follow-up images of the same patient, obtained with the same skin entrance dose, but under varying clinical conditions [28].

The EI value may be therefore used for dose containment not on a short-term individual basis, but on a longitudinal scale: while exposure indicators in individual patients may vary up to $50 \%$ despite identical skin entrance dose, the mean exposure indicator over a larger number of consecutive patients should remain constant. In case of dose creep, therefore, the mean EI will provide early feedback about changes in average patient exposure.
Kilovoltage and beam filtration

There are a number of recent studies that evaluated how far techniques assumed to be optimum for conventional imaging need to be revisited for digital radiography.

In upright film/screen chest radiography, high kilovoltage settings are used to improve penetration of the mediastinum and to reduce the attenuation of the ribs superimposing over the lung fields. Digital radiography no longer suffers from underpenetration of the mediastinum, which makes it possible to re-think the conventional approach. Image contrast increases with low $\mathrm{kVp}$, which could improve signal-to-noise ratios. In addition, detector mediums have, to an extent that depends on their absorption characteristics, a higher dose efficiency (DQE) at lower $\mathrm{kVp}$ ranges that again could be translated into improved signal to noise [29, 30, 31]. At identical effective dose to the patient, low $\mathrm{kVp}$ settings were found to increase SNR and significantly increase image quality, both in a phantom setup [30, 31, 32, 33] as well as in clinical studies $[16,32]$. Despite this, chest radiography at lower $\mathrm{kVp}$ has not seen broad clinical application. Potential downsides include increased exposure time and resulting blurring artifacts at the heart borders and increased contrast not only of pathology, but also of soft tissue compared to bones resulting in an increased visualization of anatomical background structures (such as ribs) [33].

\section{Diagnostic reference (dose) levels}

The concept of reference doses or 'diagnostic reference levels' (DRL) was introduced by the International Commission for Radiation Protection (ICRP) in the 1990s [34, 35]. DRLs are defined as patient entrance dose levels for typical examinations for groups of standard-sized patients
Fig. 7 Exposure indices for various manufacturers: note the different definitions using linear and logarithmic scales

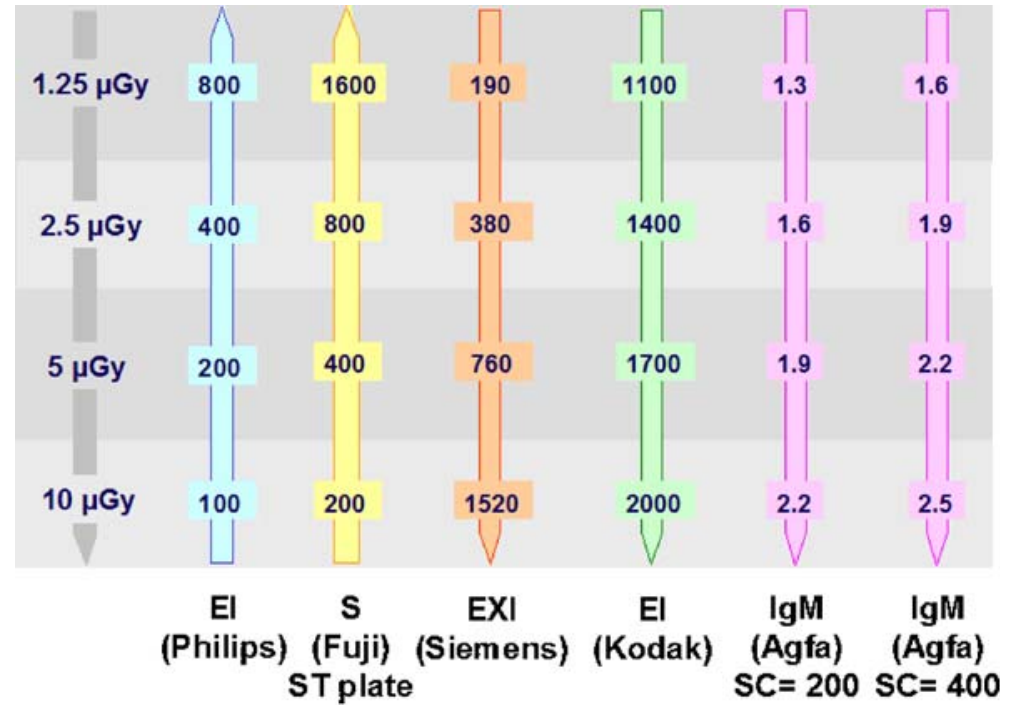


or standard phantoms for broadly defined types of equipment [34]. DRLs vary slightly for different countries and represent "state of practice" and not "state of the art." For a PA chest radiograph, the DRL varies between 0.2 and $0.3 \mathrm{mGy}$, and for the lateral projection from 1.0 to $1.5 \mathrm{mGy}$ $[27,36]$. The DRL are advisory and therefore do not distinguish between acceptable and unacceptable practice. However, if local dose values consistently exceed the DRL, an investigation into the cause should be initiated. It has to be noted that the reference levels proposed by the ICRP do not yet take into account the dose-saving potential of modern CR and DR detector technology. The chest DRL should therefore be considered an upper threshold for skin entrance exposure in digital radiography.

\section{Dose reduction: how much is possible?}

\section{ALARA principle}

In the past decades a shift has taken place from the principle of 'image quality as good as possible' to 'image quality as good as needed.' Radiation dose to patients should be as low as reasonably achievable (ALARA), while still providing image quality adequate to enable an accurate diagnosis $[37,38]$. Image quality requirements depend on the clinical question that has to be answered and therefore vary with the size, density and contrast of objects of interest relative to their background. The flexibility offered by digital radiographic systems places a lot of responsibility on technicians, physicists and radiologists for optimizing the trade-off between image quality and dose. The principle of ALARA includes the critical weighting of the indication and determining the required image quality. It also requires reorganization of the workflow because, unlike CT and fluoroscopic examinations, ordinary radiographic examinations are usually performed without the knowledge or input of the radiologist.

What constitutes 'adequate image quality' is still under discussion. Usually studies compare the performance of a new system with a 'reference system' to define the dose required with the new system for retaining equivalent image quality (Table 1). Research, however, is needed to determine the minimum level of image quality needed to reliably make or exclude a certain diagnosis. Since multiple patient exposures are not acceptable, dose reduction will have to be simulated by adding noise to a reference image. Such techniques have been published for CT [39, 40], but only start to be applied to chest radiography [41].

Implementation of ALARA was subject of international workgroups of physicists and radiologists [37, 38] who suggested three levels of image quality (high, medium and low), depending on the clinical question. A low quality level, for example, was suggested for follow-up of pneumonia in adults (see www.icrp.org) [37, 38, 42].
Because of the varying detector efficiencies, however, the actual exposure dose connected to these quality levels will vary substantially with the detector system used. Experimental evaluations showed that a medium quality level could be reached with a 400 speed film/screen system, but required a higher dose, equivalent to a speed of 200-400, for standard CR systems and a much lower dose (equivalent to a speed of 1,600) for a CsI-photodiode/TFT DR system [43].

\section{Dose and image quality in digital radiography}

The relationship between dose and image quality can be assessed quantitatively and qualitatively. The spectrum reaches from objective measurements of physical characteristics, such as modulation-transfer function (MTF), detective quantum efficiency (DQE) or contrast-noise ratio (CNR) over contrast-detail studies, anthropomorphic phantom studies to clinical studies. Studies differ in how much a radiologist's perception and abilities are involved and how well they represent the clinical situation.

Objective physical measurements in principle contain all necessary information, but they do not consider the influence of the human observer and in general it is difficult to translate the extent of differences in physical parameters into differences in clinical performance. Contrast-detail studies make it possible to compare the dose levels required to reach a certain detection level $[4,22,44]$, but the validity of these tests rely on how well they simulate reality. Anthropomorphic phantoms better approximate the clinical reality with respect to human anatomy and lesion characteristics, but cannot display the whole range of diseases. Clinical studies frequently rely on subjective scoring only and lack a good gold standard.

The majority of published studies (Table 1) apply only one methodology. There is increasing interest in how well objective measures reflect the subjective grading of image quality and how much small differences in visual grading affect diagnostic performance under clinical conditions. There are only few studies that have applied two methods such as objective measures and human observer (phantom) studies $[45,46]$ or objective measures and visual grading $[47,48]$. In most $[45,46,47]$ but not all [48] studies, the ranking of system performance was identical for both methodologies.

\section{Comparison of detector systems}

Comparison studies for dose requirements with various digital systems for chest radiography are summarized in Table 1. Differences in results appear to be dependent on the dose level, the reference technique (film/screen or CR), the statistical analysis (ROC or preference study), the type of lesions to be depicted and the study methodology 
Table 1 List of observer studies using a CD phantom or simulated lesions to compare various chest detector systems at different dose levels

\begin{tabular}{|c|c|c|c|c|c|}
\hline $\begin{array}{l}\text { Literature reference } \\
\text { (journal and year of } \\
\text { publication) }\end{array}$ & Study design* & $\begin{array}{l}\text { Reference for } \\
\text { comparison }\end{array}$ & Statistics & $\begin{array}{l}\text { Dose level } \\
(\text { speed } * *)\end{array}$ & $\begin{array}{l}\text { Results (dose savings with CsI- } \\
\text { DR in \%) }\end{array}$ \\
\hline $\begin{array}{l}\text { Aufrichtig Med Phys } \\
1999\end{array}$ & Contrast-detail & SFR vs. CsI-DR & & & 70 \\
\hline Chotas 2001 & Contrast-detail & CR vs. CsI-DR & $\mathrm{ROC}$ & & $20 \%$ \\
\hline Rong Med Phys 2000 & Contrast-detail & CR vs. SFR & CD curves & & $70-90 \%$ \\
\hline $\begin{array}{l}\text { PeerIEEE Trans Med } \\
\text { Imag } 2001\end{array}$ & Contrast-detail & CR vs. CsI-DR & $\begin{array}{l}\text { Sensitivity, } \\
\text { CD curves }\end{array}$ & $\begin{array}{l}50,100,200 \\
400,800\end{array}$ & $\begin{array}{l}\text { CsI-DR superior to DR for low- } \\
\text { contrast structures at lower dose } \\
\text { levels }\end{array}$ \\
\hline Geijer ER 2001 & Contrast-detail & $\begin{array}{l}\text { SFR vs. CR vs. CsI- } \\
\text { DR }\end{array}$ & CD curves & $\begin{array}{l}\text { SFR 160, CR } \\
200, \text { DR } 400, \\
600,800\end{array}$ & $\begin{array}{l}\text { CsI-DR vs. CR } 30 \% \text { CsI-DR vs. } \\
\text { SFR }<20 \%\end{array}$ \\
\hline $\begin{array}{l}\text { De Hauwere Rad Prot } \\
\text { Dosim } 2005\end{array}$ & Contrast-detail & $\begin{array}{l}\text { SFR vs. CR vs. CsI- } \\
\text { DR }\end{array}$ & CD curves & $\begin{array}{l}\text { Hard and soft } \\
\text { copy }\end{array}$ & $>40 \%$ \\
\hline Strotzer Inv Rad 1998 & $\begin{array}{l}\text { Simulated chest } \\
\text { lesion }\end{array}$ & SFR vs. CsI-DR & & & \\
\hline Hosch 2002 & $\begin{array}{l}\text { Phantom, simulated } \\
\text { lesions }\end{array}$ & SFR vs. CsI-DR & $\begin{array}{l}\text { Preference } \\
\text { study }\end{array}$ & $\begin{array}{l}240 \text { vs. } 48014- \\
332 \text { micro Gy }\end{array}$ & $50 \%$ \\
\hline Goo Radiol 2002 & $\begin{array}{l}\text { Phantom, simulated } \\
\text { lesions }\end{array}$ & $\begin{array}{l}\text { CsI-DR vs. CR } \\
\text { softcopy }\end{array}$ & & & \\
\hline $\begin{array}{l}\text { Uffmann Invest Rad } \\
2005\end{array}$ & $\begin{array}{l}\text { Phantomsimulated } \\
\text { chest lesions }\end{array}$ & $\begin{array}{l}\mathrm{CR} \text { (dual und single } \\
\text { reading) vs. DR }\end{array}$ & $\mathrm{ROC}$ & $\begin{array}{l}250 \text { vs. } 500 ; 400 \\
\text { vs. } 800\end{array}$ & $\begin{array}{l}\text { Dual > single CRDual CR=CsI- } \\
\text { DR }\end{array}$ \\
\hline $\begin{array}{l}\text { Redlich Radiat Prot } \\
\text { Dosim } 2005\end{array}$ & $\begin{array}{l}\text { Phantomsimulated } \\
\text { chest lesions }\end{array}$ & $\begin{array}{l}\text { CR (2K), CR (4K), } \\
\text { CsI-DR, SFR, SE }\end{array}$ & $\mathrm{ROC}$ & 400 & $\begin{array}{l}\text { CsI-DR superior CR-4K superior } \\
\text { for reticular lesions }\end{array}$ \\
\hline $\begin{array}{l}\text { Rapp-Bernhardt Radiol } \\
2003\end{array}$ & $\begin{array}{l}\text { Phantomsimulated } \\
\text { chest lesions }\end{array}$ & $\begin{array}{l}\text { CsI-DR vs. SFR } \\
\text { asymm }\end{array}$ & $\mathrm{ROC}$ & $\begin{array}{l}\text { SFR } 400 \text { DR } 400, \\
800,1,600\end{array}$ & $\begin{array}{l}\text { CsI-DR } 50 \% 400 \text { vs. } 800 \text { CsI-DR } \\
1,600 \text { inferior }\end{array}$ \\
\hline Busch ROEFO 2003 & $\begin{array}{l}\text { Contrast-detail and a } \\
\text { chest phantom }\end{array}$ & $\begin{array}{l}\text { CsI-DR vs. CR vs. } \\
\text { SFR, different CR } \\
\text { systems }\end{array}$ & CD curves & $\begin{array}{l}200,400,800 \\
1,600\end{array}$ & $>50 \%$ \\
\hline KroftAJR 2005 & $\begin{array}{l}\text { Simulated chest } \\
\text { lesions }\end{array}$ & $\begin{array}{l}\text { CR vs. CsI-DR vs. Se- } \\
\text { DR vs. CCD }\end{array}$ & Sensitivity & AEC & Dose diff $1: 4$ \\
\hline Metz Radiol 2005 & $\begin{array}{l}\text { Simultaed chest } \\
\text { lesions }\end{array}$ & CsI-DR & $\mathrm{ROC}$ & $\begin{array}{l}400,640,800 \\
100,120 \\
140 \mathrm{kV}\end{array}$ & $\begin{array}{l}50 \% \text { reduction for the lung, not } \\
\text { for the mediastinum }\end{array}$ \\
\hline Garmer AJR 2000 & $\begin{array}{l}\text { Clinical setting }(80) \\
\text { chest }\end{array}$ & SFR vs. CsI-DR & $\mathrm{ROC}$ & 400 vs. 800 & CsI-DR 50\% \\
\hline Hennigs 2001 & $\begin{array}{l}\text { Clinical setting } \\
\text { (115) chest }\end{array}$ & SFR vs. CsI-DR & $\begin{array}{l}\text { Preference } \\
\text { study }\end{array}$ & 400 & CsI-DR equiv or superior \\
\hline $\begin{array}{l}\text { Strotzer J Thoac Imag } \\
2000\end{array}$ & $\begin{array}{l}\text { Clinical setting }(15) \\
\text { chest }\end{array}$ & CsI-DR vs. SFR & $\begin{array}{l}\text { Preference } \\
\text { study }\end{array}$ & $\begin{array}{l}\text { SFR } 400 \text { CsI-DR } \\
400,800\end{array}$ & CsI-DR equiv with $50 \%$ \\
\hline Strotzer AJR 2002 & $\begin{array}{l}\text { Clinical setting }(50) \\
\text { chest }\end{array}$ & CsI-DR vs. CsI-DR & $\begin{array}{l}\text { Preference } \\
\text { study }\end{array}$ & 400 vs. 560 & $33 \%$ \\
\hline Fink AJR 2002 & $\begin{array}{l}\text { Clinical setting } \\
\text { (112) chest }\end{array}$ & SFR vs. CsI-DR & $\begin{array}{l}\text { Preference } \\
\text { study }\end{array}$ & 200 vs. 400 & $50 \%$ \\
\hline Hermann ER 2002 & $\begin{array}{l}\text { Clinical setting }(75) \\
\text { chest }\end{array}$ & CR vs. CsI-DR & $\begin{array}{l}\text { Preference } \\
\text { study }\end{array}$ & 400 vs. 800 & $50 \%$ \\
\hline Loewe ER (suppl) 2002 & $\begin{array}{l}\text { Clinical setting (40) } \\
\text { simulated lesions } \\
\text { chest }\end{array}$ & CR vs. CsI-DR & ROC & 400 vs. 800 & $50 \%$ \\
\hline
\end{tabular}


Table 1 (continued)

\begin{tabular}{|c|c|c|c|c|c|}
\hline $\begin{array}{l}\text { Literature reference } \\
\text { (journal and year of } \\
\text { publication) }\end{array}$ & Study design* & $\begin{array}{l}\text { Reference for } \\
\text { comparison }\end{array}$ & Statistics & $\begin{array}{l}\text { Dose level } \\
(\text { speed } * *)\end{array}$ & $\begin{array}{l}\text { Results (dose savings with CsI- } \\
\text { DR in \%) }\end{array}$ \\
\hline Gruber ER 2006 & $\begin{array}{l}\text { Clinical setting }(50) \\
\text { chest }\end{array}$ & CR vs. DR & $\begin{array}{l}\text { ROC and } \\
\text { preference } \\
\text { study }\end{array}$ & $\begin{array}{l}250 \text { vs. } 500 ; 400 \\
\text { vs } 800\end{array}$ & $50 \%$ each \\
\hline Ganten AJR 2003 & & SFR vs. cr vs. CsI-DR & & & \\
\hline Bacher AJR 2003 & $\begin{array}{l}\text { Clinical setting } \\
(3 \times 100) \text { chest }\end{array}$ & $\begin{array}{l}\text { FSR vs. CR vs. CsI- } \\
\text { DR }\end{array}$ & $\begin{array}{l}\text { Preference } \\
\text { study }\end{array}$ & 400 & $\begin{array}{l}\text { Approx. } 40 \% \text { vs. CR, approx. } \\
55 \% \text { vs. SFR }\end{array}$ \\
\hline Bacher AJR 2003 & $\begin{array}{l}\text { Clinical setting } \\
(2 \times 100) \text { chest }\end{array}$ & CsI-DR vs. Se-DR & $\begin{array}{l}\text { Preference } \\
\text { study }\end{array}$ & 400 & $50 \%$ for $\mathrm{PA}$ and $35 \%$ for the lat \\
\hline $\begin{array}{l}\text { Fischbach Acta Rad } \\
2003\end{array}$ & & CsI-DR vs. Se-DR & & & \\
\hline
\end{tabular}

CsI-based $\mathrm{DR}=$ indirect flat panel direct radiography $(\mathrm{CsI} / \mathrm{a}-\mathrm{Si}), \mathrm{SFR}=$ screen/film radiography, $\mathrm{CR}=$ computed radiography, $\mathrm{ROC}=$ receiveroperating characteristics

*Number of patients in parenthesis

**Based on its definition in film/screen "speed" should not be used to describe the dose that was applied to acquire digital radiographs. Yet, it is frequently used in publications and means that the exposure parameters or the automatic exposure control (AEC) were set as for images with a conventional film of the corresponding speed

(phantom or clinical study). Results can be summarized as follows:

1. Even the most recent generation of single-sided read storage phosphor plates does not allow for dose reduction relative to a 400 speed film/screen system [44].

2. Dual-readout $\mathrm{CR}$ is more dose-efficient than single read-out CR. Detection of simulated lesions in the lung fields were as high as in CsI-DR, but lesion detection in high absorption areas was inferior to DR [44].

3. DR systems based on indirect conversion (CsIphotodiode/TFT technology) are more dose-efficient than direct-conversion systems (a-Se/TFT technology) by a factor of 2 for frequencies below 4 cycles $/ \mathrm{mm}$ [17].

4. In clinical settings, dose savings with CsI-based DR are $30-50 \%$ compared to a 400 -speed film/screen system $(2.5 \mu$ Gy detector dose) (Table 1) (Fig. 8). Dose savings are limited by the performance in high absorption areas (retro-cardiac, infra-diaphragmatic areas), but can exceed $50 \%$ in the lung fields (Table 1).

5. Due to effective scatter reduction CCD slot scanning techniques provide an image quality comparable to that of CsI-DR systems. Dose requirements of CCD slot scanning techniques are higher than those of CsI-based DR systems, but lower than those of standard CR or screen/film radiography $[22,23]$.

When interpreting and comparing these results, it is important to consider the following aspects:

- Specification of an imaging system as 'CR' or 'DR' is not enough: more information is needed because of the varying dose efficiency (e.g., indirect versus direct conversion DR, CsI versus Gadox scintillator, dual versus single read-out $\mathrm{CR}$, needle versus amorphous detector).

- Comparison of performance vary with the dose level at which images were obtained: while comparison at high dose levels may not reveal a difference, relevant differences may become apparent at low dose levels. For example, CsI-based DR showed its superiority over standard-CR for the detection of low-density lesions, especially at lower dose levels [49].

- Type of lesion (e.g., interstitial versus patchy lung infiltration), location in a low or high absorption areas (lung fields versus retrocardiac area) and lesion conspicuity (obvious versus subtle) greatly influence lesion detectability and therefore performance measures.

- The impact of digital image processing on the visibility of lesions is well known. In any study-whether phantom or clinical study-the applied processing has to be clearly defined.

\section{Advances in image processing}

Image processing critically influences image quality: automated windowing can provide optimum image density independent of exposure, adjustments of the gradation curves can simulate the characteristics of arbitrary film/ screen systems, and frequency processing can enhance local contrast or even selectively enhance structures of a certain size or contrast. 


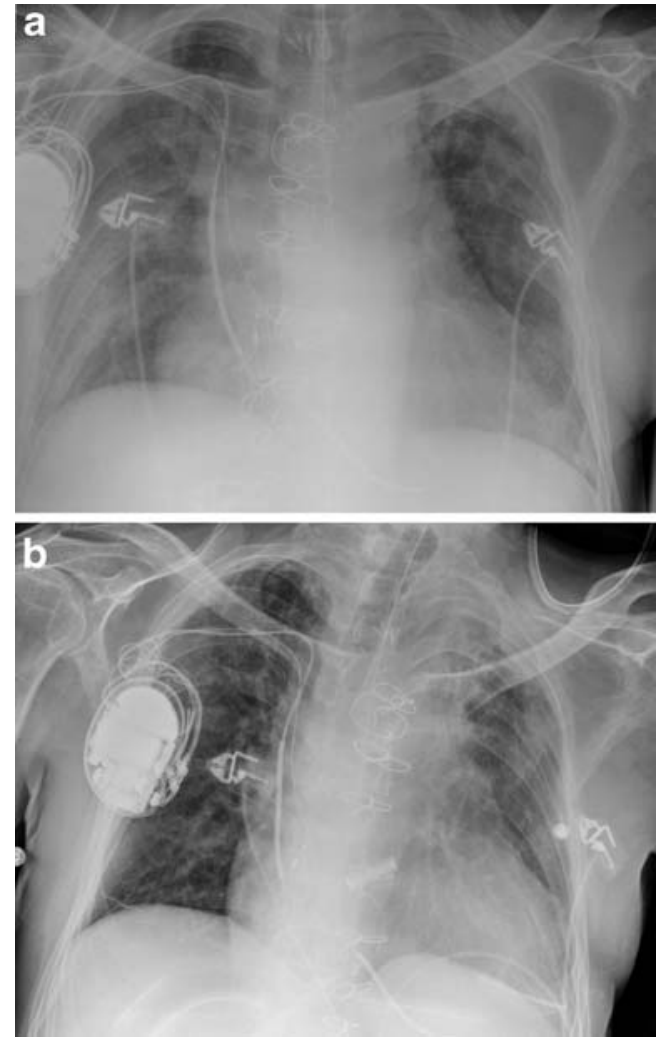

Fig. 8 Two follow-up bed-side chest radiographs in the same ICU patient obtained with standard dose CR (single read-out, a) and 50\% dose reduced DR (CsI-TFT, b)

Unsharp mask filtering is the simplest type of frequency processing, but has the disadvantage that stronger filter settings lead to (edge) artifacts. Most vendors have made the transition to multi-frequency processing algorithms (e.g., MUSICA, UNIQUE, MFP), which better achieve enhancement of low-density structures and subtle pathology $[50,51]$. Multifrequency processing makes it possible to separately enhance and suppress image structures dependent on their contrast (amplitude), their size (spatial frequency bands) and their background density (mediastinum versus lung). The result is an 'image harmonization' with a more transparent mediastinum and improved visualization of low-contrast structures throughout the chest [52] (Fig. 9).

The most advanced processing algorithms aim at analyzing images (CAD), selectively enhancing bones and soft tissues (dual-energy subtraction), and at visualizing change at follow-up (temporal subtraction) [53]. They are described below.

\section{Computer-aided diagnosis (CAD)}

Computer-aided diagnosis (CAD) programs have the goal to aid the radiologist in detecting or differentiating various disease entities in the chest. Usually the system suggests a lesion or abnormal region that then has to be verified by the radiologist. Early versions of CAD systems suffered from unacceptably high false-positive rates. Recent results with nodule CAD (Fig. 10), however, demonstrated increased sensitivity for small lung nodules $(5-15 \mathrm{~mm})$ and decreased inter-observer variability at false-positive rates of two or three lesions per PA radiograph $[54,55,56]$.

The role of CAD is continuously evolving. In an environment with ever-increasing time pressure on radiologists, CAD may assume the role of a control mechanism that alerts radiologists to potential abnormalities. Impact of CAD on radiologist's behavior and the role of reader experience are currently under discussion [57].
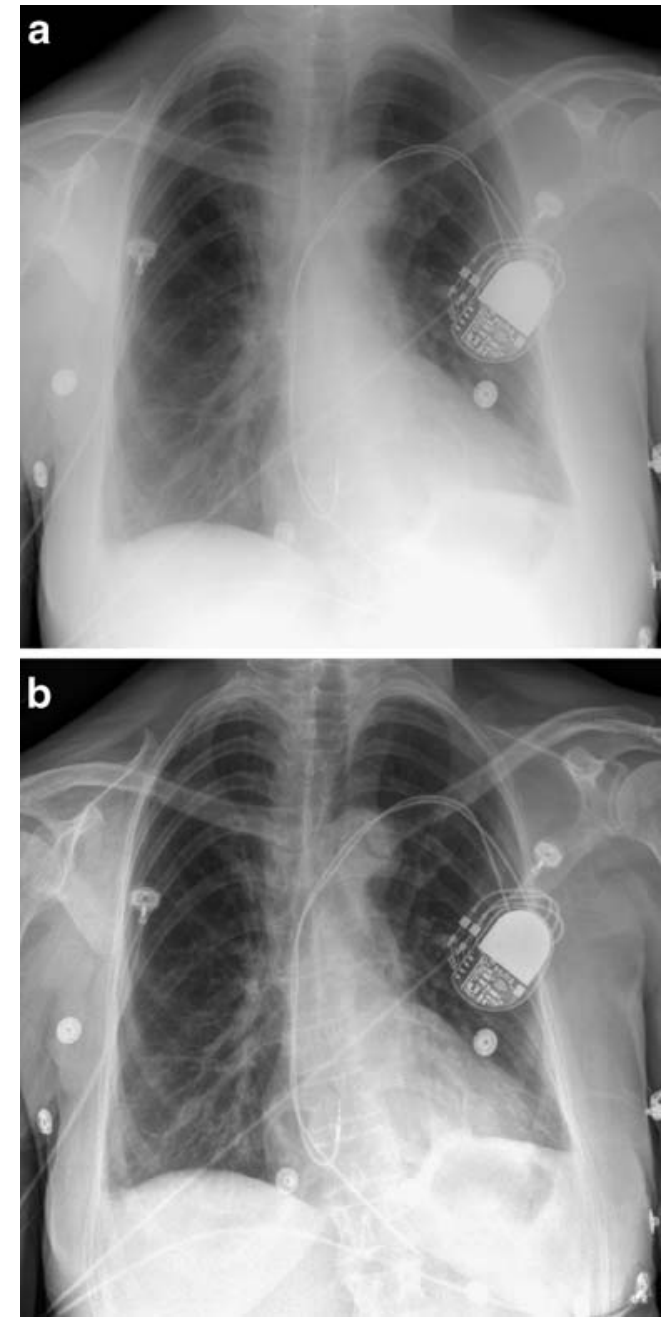

Fig. 9 Two postero-anterior chest radiographs of a patient after pacemaker implantation: a was processed using simple unsharp masking, b was processed using an elaborate non-linear multifrequency processing 


\section{Dual-energy subtraction}

Dual-energy subtraction radiography involves taking a chest exposure at two different X-ray energies. By exploiting the difference in energy dependence of attenuation between bone and soft tissue, either bone or soft tissues can be eliminated by locally weighted subtraction of the two images. In order to get optimum separation of bone and soft tissues, scatter and beam hardening has to be corrected for. Subtraction increases the noise in the images substantially; this increase is less when the energy separation is good, but even then sophisticated noise reduction techniques are required to achieve diagnostic quality $[58,59]$. Dual-energy subtration was found to increase the detection rate of intrapulmonary nodules by 'subtracting' overlying and potentially distracting rib structures [60].

Two acquisition techniques are available. The singleexposure technique uses a stack of two detectors (usually storage phosphor screens) with a beam-hardening filter (usually copper) in between. Energy separation between the front low-energy and the back high-energy image is modest and results in higher image noise, but there are no misregistration problems. The dual-exposure technique relies on two separate chest exposures in rapid succession (200 ms) at low and high $\mathrm{kVp}$ settings. It has a better energy separation, but suffers from slight misregistration artifacts.

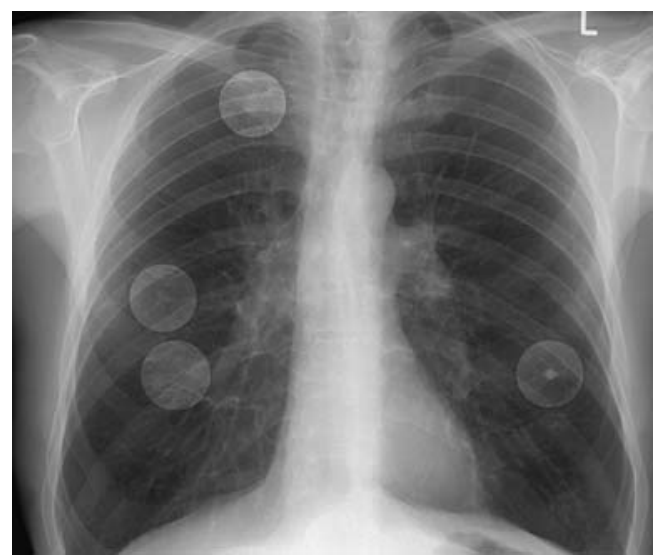

Fig. 10 PA chest radiograph with computer-aided detection (CAD) marks: catch of an obvious nodule in the left lung and two subtle nodules in the right lung. One false-positive mark in the right lung apex on crossing of bone structures
Dual-energy subtraction allows for differentiation of calcified and non-calcified lesions, improved detection of nodules and masses, especially in critical areas, and improved detection of rib lesions $[58,59]$. Although all results of clinical studies are positive, dual-energy subtraction has not yet seen widespread use in routine practice. The artifacts seen in earlier versions are now less of a problem, but the fact that a dual-energy technique requires the radiologist to routinely view three images (standard, bone and soft tissue) instead of one radiograph may explain the reluctance to use it. With better integration into monitor reading on PACS workstations, this problem may be overcome soon.

\section{Temporal subtraction}

Temporal subtraction is a processing technique based on the matching and subsequent subtraction of a follow-up radiograph and a baseline image. Because the rib cage moves differently than the lungs, the matching process is complex and can induce misregistration artifacts. The technique is powerful in revealing subtle interval changes and improves detection of nodules and hazy infiltrates [61, 62]. A recent publication reported reduction of subtraction artifacts when combining dual-energy soft tissue images with temporal subtraction [63]. At present, temporal subtraction algorithms are commercially available only in Japan.

\section{Digital tomosynthesis}

Digital tomosynthesis evolved from conventional tomography: during motion of the X-ray tube, multiple projection images from the patient are obtained. These projection images are subsequently shifted and added to bring objects in a given plane into focus, while other structures are spread across the image and are rendered with varying amounts of blur [64]. Tomosynthesis has been shown to improve visibility of intrapulmonary nodules, but this technique is so far limited to few institutions. The assessment of its role in a larger patient group is the topic of an ongoing study in the US.

Open Access This article is distributed under the terms of the Creative Commons Attribution Noncommercial License which permits any noncommercial use, distribution, and reproduction in any medium, provided the original author(s) and source are credited. 


\section{References}

1. International commission on radiological protection (2004) Managing patient dose in digital radiology. ICRP publication 93 Annals of the ICRP, Elsevier, $\mathrm{p} 21$

2. Samei E (2003) Performance of digital radiographic detectors: quantification and assessment methods. Advances in digital radiography: RSNA 2003: Categorical course in diagnostic Radiology Physics, pp 37-47

3. Arakawa S, Itoh W, Kohda K et al (1999) Novel computed radiography system with improved image quality by detection of emissions from both sides of an imaging plate. SPIE Medical Imaging, poster presentation

4. Uffmann M, Prokop M, Eisenhuber E et al (2005) Computed radiography and direct radiography: Influence of acquisition dose on the detection of simulated lesions. Invest Radiol 40(5):24956

5. Schaetzing R, Fasbender R, Kersten $P$ (2002) New high-speed scanning technique for computed radiography. SPIE 4682:511-520

6. Leblans P, Struye L, Willems P et al (2000) A new needle-crystalline computed radiography detector. J Digit Imaging 13(2 Suppl 1):117-120

7. Frankenberger J, Mair S, Herrmann C et al (2005) Reflective and transmissive CR scan head technology on needle image plates. In: Flynn MJ (ed) Medical imaging. Physics of Medical Imaging 5745(1):499-510

8. Koerner M, Wirth S, Treitl $M$ et al (2005) Initial clinical results with a needle screen storage phosphor system in chest radiograms. ROEFO 177:1491-1496

9. Koerner M, Treilt M, Schaetzing R et al (2006) Depiction of low contrast detail in digial radiography: comparison of powder and needle-structured stiorage phosphor systems. Invest Radiol 41 (7):593-599

10. Flynn MJ, Samei E (1999) Experimental comparison of noise and resolution for $2 \mathrm{~K}$ and $4 \mathrm{~K}$ storage phosphor radiography systems. Med Phys 26:1612-1623

11. Samei E, Flynn MJ (2002) An experimental comparison of detector performance for computed radiography systems. Med Phys 29(4):447-459
12. Miro S, Leung A, Rubin G et al (2001) Digital storage phosphor chest radiography: An ROC study of the effect of $2 \mathrm{~K}$ versus $4 \mathrm{~K}$ matrix size on observer performance. Radiology 218:527-532

13. Koelblinger C, Prokop M, Weber M et al (2007) $2 \mathrm{~K}$ versus $4 \mathrm{~K}$ storage phosphor chest radiography: detection performance and image quality. Eur Radiol 17(11):2934-2940

14. Ueguchi $\mathrm{T}$, Johkoh $\mathrm{T}$, Tomiyama $\mathrm{N}$ et al (2005) Full-size digital storage phosphor chest radiography: effect of $4 \mathrm{~K}$ versus $2 \mathrm{~K}$ matrix size on observer performance in detection of subtle interstitial abnormalities. Radiat Med 23(3):170-174

15. Samei E, Flynn MJ (2003) An experimental comparison of detector performance for direct and indirect digital radiography systems. Med Phys 30 (4):608-622

16. Metz S, Damoser P, Hollweck R et al (2005) Chest radiography with a digital flat-panel detector: experimental receiver operating characteristic analysis. Radiology 234(3):776-784

17. Bacher K, Smeets P, Vereecken L et al (2006) Image quality and radiation dose in digital chest imaging: comparison of an amorphous silicon and an amorphous selenium flat-panel system. AJR 187(3):630-637

18. Bath M, Sund P, Mansson LG (2002) Evaluation of the imaging properties of two generations of a CCD based system for digital chest radiography. Med Phys 29:2286-2297

19. Lawinski C, Mackenzie A, Cole $\mathrm{H}$ et al (2005) Digital detectors for general radiography: a comparative technical report. National Health Service report 05078. K-CARE web site.http/www. kcare.co.uk/publkications/abstracts/ report05078.htm

20. Samei E, Saunders RS, Lo JY et al (2004) Fundamental imaging characteristics of a slot scan digital chest radiographic system. Med Phys 31 (9):2687-2698

21. Kroft LJM, Geleijns J, Mertens BJA et al (2004) Digital slot scan charge coupled device radiography versus AMBER and Bucky screen-film radiography for detection of simulated nodules and interstitial disease in a chest phantom. Radiology 231:156163

22. Veldkamp WJH, Kroft LJM, Boot MV et al (2006) Contrast-detail evaluation and dose assessment of eight digital chest radiography systems in clinical practice. Eur Radiol 16(2):333-341
23. Kroft LJM, Veldkamp WJH, Mertens BJA et al (2005) Comparison of eight different digital chest radiography systems: variation in detection of simulated chest disease. AJR 185:339-346

24. Weatherburn GC, Bryan S, Davies JG (2000) Comparison of doses for bedside examinations of the chest with conventional screen-film and computed radiography: results of a randomized controlled trial. Radiology 217:707712

25. Willis CE (2002) Computed radiography: a higher dose? Pediatr Radiol 32:745-750, discussion 751-4

26. Eisenhuber E, Stadler A, Prokop M et al (2003) Detection of monitoring materials on bedside chest radiographs with the most recent generation of storage phosphor plates: dose increase does not improve detection performance. Radiology 227(1):216-221

27. Schuncke A, Neitzel U (2005) Retrospective patient dose analysis of a digital radiography system in routine clinical use. Rad Prot Dosim 114(13):131-134

28. Coulibaly-Wimmer M, Prokop M, Schaefer-Prokop C (2000) Usefulness of the S-value to monitor exposure dose in digital radiography: results of a phantom study. Eur Radiol Suppl 1 to Vol 10 Number 2:264 (abstract 1108)

29. Launders JH, Cowen AR (1995) A comparison of the threshold detail detectability of a screen-film combination and computed radiology under conditions relevant to high-kVp chest radiography. Phys Med Biol 40:13931398

30. Chotas HG, Floyd CE, Dobbins JT, Ravin CE (1993) Digital chest radiography with photo-stimulable storage phosphors: signal-to-noise ratio as a function of kilo-voltage with matched exposure risk. Radiology 186:395-398

31. Honey ID, Mackenzie A, Evans DS (2005) Investigation of optimum energies for chest imaging using filmscreen and computed radiography. Br J Radiol 78(929):422-427

32. Uffmann M, Neitzel U, Prokop M et al (2005) Flat-panel-detector chest radiography: effect of tube voltage on image quality. Radiology 235(2):642650 
33. Ullmann G, Sandberg M, Dance DR et al (2006) Towards opimization in digital chest radiography using Monte Carlo modeling. Phys Med Biol 51:2729-2743

34. Recommendations of the International Commission on Radiological Protection (1991) ICRP Publication 60. Annals of the ICRP 21, No. 1-3

35. Radiological protection and safety in medicine (1996) ICRP Publication 73 Annals of the ICRP 26, No. 2

36. Wall BF (2004) Diagnostic reference levels in the x-ray department. Eur Radiol Syllabus 14:66-73

37. Vano E (2005) ICRP recommendations on "managing patient dose in digital radiology"(invited paper). Radiat Prot Dos 114(1-3):126-130

38. Busch HP, Faulkner K (2006) Image quality and dose management in digital radiography: a new paradigm for optimization. Radiat Prot Dos 117(13):143-147

39. Tack D, De Maertelaer V, Petit W et al (2005) Multi-detector row CT pulmonary angiography: comparison of standard-dose and simulated low-dose techniques. Radiology 236(1):318-25

40. Bankier AA, Schaefer-Prokop C, De Maertelaer V et al (2007) Air trapping: comparison of standard-dose and simulated low-dose thin-section CT techniques. Radiology 242(3):898-906

41. Kroft LJ, Veldkamp WJ, Mertens BJ et al (2006) Detection of simulated nodules on clinical radiographs: dose reduction at digital postero-anterior chest radiography. Radiology 241(2):392398

42. International commission on Radiological protection (2004). Managing patient dose in digital radiology. ICRP publication 93 Annals of the ICRP, Elsevier, pp 58

43. Busch HP, Busch S, Decker C, Schilz C (2003) Image quality and exposure dose in digital projection radiography (german). ROEFO 175(1):32-37
44. Doyle P, Martin CJ, Gentle D (2005) Dose-image quality optimization in digital chest radiography. Radiat Prot Dosimetry 114(1-3):269-272

45. Redlich U, Hoeschen C, Effenberger O et al (2005) Comparison of four digital and one conventional radiographic image systems for the chest in a patient study with subsequent system optimization. ROEFO 177(2):272-278

46. Gruber M, Uffmann M, Weber $M$ et al (2006) Direct detector radiography versus dual reading computed radiography: feasibility of dose reduction in chest radiography. Eur Radiol 16 (7):1544-1550

47. De Hauwere A, Bacher K, Smeets P et al (2005) Analysis of image quality in digital chest imaging. Radiat Prot Dosimetry 117(1-3):174-177

48. Sund P, Bath M, Kheddache S, Mansson LG (2004) Comparison of visual grading analysis and determination of detective quantum efficiency for evaluating system performance in digital chest radiography. Eur Radiol 14 (1):48-58

49. Peer S, Neitzel U, Giacomussi SM et al (2001) Comparison of low contrast detail perception on storage phosphor radiographs and digital flat panel detector images. IEEE Trans Med Imag 20:239-242

50. Stahl M, Aach T, Dippel S (2000) Digital radiography enhancement by nonlinear multiscale processing. Med Phys 27:56-65

51. Vuylsteke P, Schoeters E (1994) Multiscale image contrast amplification (MUSICA). Proc SPIE medical imaging 2167:551-560

52. Hoeppner S, Maack I, Neitzel U, Stahl M (2002) Equalized contrast display processing for digital radiography. In: Medical imaging: visualization, imageguided procedures, and display, 4681 (1):617-625

53. MacMahon H (2003) Dual-energy and temporal subtraction digital chest radiography. Advances in digital radiography: RSNA 2003 Categorical course in diagnostic radiology physics pp 181188

54. Kakeda S, Moriya J, Sato H et al (2004) Improved detection of lung nodules on chest radiographs using commercial computer-aided diagnosis system. AJR 182:505-510
55. Sakai S, Soeda H, Takahashi N et al (2006) Computer aided nodule detection on digital chest radiography: Validation test on consecutive T1 cases of resectable lung cancer. Journ of Digit Imag 19(4):376-382

56. Kobayashi T, Xu XW, MacMahon $\mathrm{H}$ et al (1996) Effect of a computer-aided diagnosis scheme on radiologists performance in detection of lung nodules on radiographs. Radiology 199:843848

57. Freedman MT, Lo SCP, Osicka T et al (2002) Computer aided detection of lung cancer on chest radiographs: effect of machine CAD false positive locations on radiologists behaviors. Proc SPIE 4684:1311-1319

58. MacMahon H (2000) Improvement in detection of pulmonary nodules: digital image processing and computer-aided diagnosis. Radiographics 20(4):11691177

59. Gilkeson RC, Sachs PB (2006) Dual energy subtraction digital radiography: technical considerations, clinical applications, and imaging pitfalls (review). J Thorac Imag 21(4):303-313

60. Uemura M, Miyagawa M, Yasuhara Y et al (2005) Clinical evaluation of pulmonary nodules with dual-exposure dual-energy subtraction chest radiography. Radiat Med 23(6):391-397

61. Tsubamoto M, Johkoh T, Kozuka T et al (2002) Temporal subtraction for the detection of hazy pulmonary opacities on chest radiography. AJR 179:467-471

62. Johkoh T, Kozuka T, Tomiyama $\mathrm{N}$ et al (2002) Temporal subtraction for detection of solitary pulmonary nodules on chest radiographs: evaluation of a commercially available computer-aided diagnosis system. Radiology 223:806811

63. Armato SG, Doshi DJ, Engelmann R et al (2006) Temporal subtration of dualenergy chest radiographs. Med Phys 33 (6):1911-1919

64. Dobbins JT, Godfrey DJ, McAdams HP (2003) Chest tomosynthesis. Syllabus RSNA 2003, Advances in digital radiography: RSNA categorical course in diagnostic radiology physics $211-217$ 